\title{
Expression of CD45RO on circulating CD19+ B-cells in Crohn's disease
}

\author{
B R Yacyshyn, L M Pilarski
}

\begin{abstract}
Crohn's disease is an immunoregulatory disorder of the intestine that can be associated with systemic manifestations. This study analysed B-cell differentiation antigens to identify B-cell subpopulations unique to patients with Crohn's disease. CD45 isoform expression was used as an indicator of B-cell differentiation stage. This work shows that B-cells in blood and gut of patients with Crohn's disease are at an advanced stage of differentiation based on their unusual presentation of transitional (RA $+\mathbf{R O}+)$ and late stage $(\mathbf{R O}+) \mathbf{C D} 45$ isoforms on lamina propria lymphocytes, whereas normal intestinal lamina propria lymphocytes B-cells express primarily CD45RA. Crohn's disease patients had heightened expression of the CD45RO isoform on CD19+ lamina propria lymphocytes, and was found in a statistically significant proportion of Crohn's peripheral blood mononuclear cells (PBMC) where CD19+ PBMC had an expression pattern affecting an unexpectedly high proportion of these differentiated or late stage CD45RO+ B-cells. The expression of CD45RO varied greatly among CD19+ PBMC from patients with Crohn's disease, so multiple regression analysis was performed between these CD45 isoforms and several clinical parameters. After grouping high and low CD45RO expression on CD19+ B-cells, a significant statistical difference was found between high Crohn's disease activity index (CDAI) and low CDAI Crohn's disease patients respectively.

(Gut 1993; 34: 1698-1704)
\end{abstract}

The inflammatory bowel diseases Crohn's disease and ulcerative colitis are intestinal disorders of unknown causes. The clinical presentations of these two illnesses can be so similar as to prohibit their differentiation pathologically in a number of patients.' Specific aberrations of the mucosal immune system have been identified in inflammatory bowel disease (IBD) patients. For instance, a predominance of $\mathrm{CD} 4+$ and lymphokine activated killer lymphocytes together with a comparative deficiency of CD8+ cells has been found among Crohn's lamina propria lymphocytes. ${ }^{2}$ This same study identified a decrease in CD45RA + CD4+ in lamina propria lymphocytes compared with peripheral blood mononuclear cells (PBMC). Lamina propria lymphocytes from patients with IBD have been found to have heightened expression of activation markers (including transferrin receptor, IL-2 receptor and 4F2). ${ }^{3-5}$ Humoral immune abnormalities in IBD affect various autoantibodies including rheumatoid factor, anti-colon antibodies, and neutrophil autoantibodies disputedly secondary to the underlying mucosal inflammation and not a primary pathophysiological factor..$^{6-8}$

In this study we analysed the phenotypes of B and $T$ cells from patients with IBD, with an emphasis on changes in the B-cells populating the lamina propria in comparison with those in PBMC, emphasising the selective expression of CD45 isoforms as a marker for differentiation within the B-cell lineage (reviewed in ref 9) and analysis of CD5 and CD11b, which have been associated with autoimmune B-cells or the activation state of the B-cell. ${ }^{10} \mathrm{CD} 45$, the leucocyte common antigen, is the most prevalent antigen on the surface of $B$ and $T$ lymphocytes and through its cytoplasmic domain, the tyrosine phosphatase activity plays a key part in intracellular signalling." The CD45 isoforms, CD45RA and CD45RO are distinguished by differences in molecular weight, glycosylations and are encoded by alternatively spliced mRNA. ${ }^{12-14}$ These isoforms characterise T-cell differentiation with the transition from expression of high molecular weight CD45RA (p220) isoform on naive cells to the low molecular weight CD45RO (p180) isoform on memory T-cells. ${ }^{15}{ }^{16} \mathrm{~A}$ recent study of this group of cell surface molecules in normal human intestinal mucosal $\mathrm{CD} 3+\mathrm{T}$-cells has shown that the intraepithelial lymphocyte population expressed mainly CD45RO. ${ }^{17} \mathrm{CD} 3+\mathrm{CD} 45 \mathrm{RO}+\mathrm{T}$-cells are probably memory $\mathrm{T}$-cells consistent with their role as primary immune regulators of an antigen bombarded environment such as the gut. B-Cells are also found, however, among the mucosal lymphocytes in normal and disease states. We have recently identified among B-cells a similar transition in CD45 isoforms to that found in T-cells. ${ }^{918}{ }^{19}$ Pre B cells express exclusively CD45RA at low density with an increase in CD45RA density as differentiation proceeds towards mature B-cell function (reviewed in ref 9). A transition from CD45RA to CD45RO expression seems to occur on in vivo antigen stimulated B-cells, which has been confirmed by in vitro studies. ${ }^{18} 19$ Early plasma cells express only the low molecular weight CD45 isoforms, while end stage plasma cells eventually lose all CD45 expression. ${ }^{19}$

In this study, PBMC or lamina propria lymphocytes, or both have been characterised in Crohn's disease, ulcerative colitis (UC), coeliac sprue, and normal patients. Crohn's PBMC were studied by multiple regression analysis in relation to a number of clinical parameters corresponding to the patients studied. From our findings in this study, we show that analysis of CD45 isoforms can identify subpopulations with possible functional significance, of $B$ and $T$ 
lymphocytes in lamina propria lymphocytes and PBMC.

\section{Materials and methods}

PATIENTS AND CONTROLS

Specimens of the colon from patients with Crohn's disease and ulcerative colitis were obtained with the assistance of a pathologist to sample disease affected mucosa. Normal mucosa was obtained from the colon at least $15 \mathrm{~cm}$ distal to carcinoma in patients having resection as well as from normal areas in patients having resection for diverticulosis. Normal colon was also obtained from decreased persons donating organs for transplantation. A total of 10 'normal', eight Crohn's disease, and four ulcerative colitis colons were analysed. Peripheral blood was analysed from patients with Crohn's disease $(n=33)$, as well as patients with ulcerative colitis $(n=11)$, coeliac sprue $(n=13)$, and normal Red Cross blood donor controls $(n=9)$.

Many of the patients with Crohn's disease were enrolled in the MRC Canadian Crohn's Relapse Prevention Trial, and all had diagnoses established clinically and through pathological and radiological criteria. These patients were receiving various drugs, but primarily 5-acetylsalicylic acid and sulphasalazine. Patients studied were not receiving immunomodulatory drugs. Protocols were approved by the ethics committee of the Faculty of Medicine, University of Alberta.

\section{PERIPHERAL BLOOD MONONUCLEAR CELL ISOLATION}

PBMC were obtained with informed consent from 33 patients with Crohn's disease, as well as patients with UC, coeliac sprue, and normal Red Cross blood donors. PBMC were purified by centrifugation over Ficoll Paque (Pharmacia, Dorval, PQ) followed by two washes.

\section{ISOLATION OF LAMINA PROPRIA LYMPHOCYTES} Normal large bowel intestinal mononuclear cells were obtained from surgically removed specimens from subjects donating organs for transplantation, from patients with diverticulosis, as well as from morphologically normal areas of large bowel at least $15 \mathrm{~cm}$ distal to diseased areas of colons resected for adenocarcinoma. Crohn's intestinal mononuclear cells were obtained from colonic specimens from patients having resections done for therapeutic reasons. UC intestinal mononuclear cells were similarly obtained from the colons of patients having therapeutic resections. Intestinal mononuclear cells were isolated from mucosa according to a well established protocol as follows. ${ }^{50-22}$ Briefly, specimens were washed in RPMI media, the mucosa then dissected from submucosa. Mucosa was then cut into small $0.5 \mathrm{~cm} \times 0.5 \mathrm{~cm}$ minced pieces and washed repetitively in Hanks's balanced salt solution without calcium and magnesium containing antibiotics $1 \mathrm{mg} / \mathrm{ml}$ Ticarcillin (Beecham, Pointe-Claire, Canada), $0.5 \mathrm{mg} / \mathrm{m}$ Amikacin (Bristol Labs, Ottawa, Canada), 0.4\% Septra (Burroughs-Wellcome, Kirkland, Canada),
$2 \mathrm{mg} / \mathrm{ml}$ Fungizone Grand Island Biological Co (Gibco, Grand Island, USA), $10 \mathrm{~mm}$ hydroxyethyl piperazine-ethane sulphonic acid (HEPES), and $\mathrm{NaOH}$ to adjust to $\mathrm{pH} 7 \cdot 4$. The minced pieces were stirred in multiple changes of media containing $0.75 \mathrm{~m}$ EDTA (Sigma, St Louis, USA) and $5 \%$ heat inactivated pooled human serum to remove epithelial cells. The tissue was then incubated overnight in Hanks's balanced salt solution collagenase medium containing $16 \mu / \mathrm{ml}$ chromatographically purified collagenase (Worthington Biochemical, Freehold, USA) and $20 \%$ heat inactivated pooled human serum. After collagenase digestion, cells were layered over a ficoll hypaque gradient (specific gravity (sg) 1.077) and centrifuged at $400 \mathrm{~g}$ for 20 minutes. The interface was collected, diluted with Hanks's balanced salt solution, and resuspended in $10 \mathrm{ml}$ Percoll solution (sg 1.040, Pharmacia, Piscataway, USA), and centrifuged at $500 \mathrm{~g}$ for 15 minutes to remove dead cells and debris. These cells were then washed through fetal bovine serum gradients and counted.

\section{ANTIBODIES}

The CD45 common determinant marker (HLEFITC), Leu 15-PE (CD11b), and the control antibodies IgG1-FITC, IgG-PE, IgG2a-FITC, and IgG2a-PE were purchased from BectonDickinson (Mountain View, California). B4FITC, B4-RD1 (CD19), B1-FITC or B1-RD1 (CD20), and T1-RD1 (CD5) were purchased from Coulter (Hialeah, Florida). Biotinylated goat anti-mouse immunoglobulin and Tandem avidin were purchased from Southern Biotechnology (Birmingham, Alabama). UCHLI (CD45RO) was a generous gift of Dr P Beverley. Monoclonal antibodies to CD45RA were CD45RA FITC, purchased from GEN Track (Wayne, Pennsylvania) and FMC44-PE. ${ }^{23} 24$

The specificity of most CD45 antibodies used here was confirmed by their ability to precipitate bands having the appropriate molecular weights $^{25}$ (unpublished data) and all were tested for their reactivity with a panel of CD45 transfectants. ${ }^{26}$

\section{THREE COLOUR IMMUNOFLUORESCENCE}

Cell surface antigens present on the isolated mononuclear cells were evaluated by three colour immunofluorescence using a four stage combined direct and indirect staining procedure. In stage (a) cells were stained with an uncoupled antibody; (b) secondly with goat antimouse biotin (Jackson); (c) blocked with mouse Ig (Jackson), $1 \mu \mathrm{g} / \mathrm{ml}$; and (d) stained with Streptavidin-Tandem, together with the two remaining antibodies directly conjugated to either FITC or PE. Mononuclear cells were resuspended in $50 \mu$ l of uncoupled monoclonal antibody diluted roughly in phosphate buffered saline containing $0.5 \%$ bovine serum albumin and $0.02 \%$ sodium azide. The cells were incubated for 30 minutes at $4^{\circ} \mathrm{C}$, spun down, and washed twice in buffer solution, and incubated for $\mathbf{1 0}$ minutes at room temperature, spun down and resuspended in $20 \mu \mathrm{l}$ Streptavidin-Tandem. The other two monoclonal antibodies coupled to 
TABLE I CD3+ Mucosal lymphocytes

\begin{tabular}{|c|c|c|c|c|}
\hline & $\underset{(\%)}{C D 45 R A+R O-}$ & $\begin{array}{l}R A+R O+ \\
(\%)\end{array}$ & $\begin{array}{l}R A-R O+ \\
(\%)\end{array}$ & $\begin{array}{l}R A-R O- \\
(\%)\end{array}$ \\
\hline $\begin{array}{l}\text { Crohn's disease }(n=8) \\
\text { Ulcerative colitis }(n=4) \\
\text { Normal }(n=10)\end{array}$ & $\begin{array}{r}23(6)^{\star} \\
22(9)^{\star} \\
9(2)^{\star}\end{array}$ & $\begin{array}{l}20(6) \\
9(5)^{\star} \\
19(4)\end{array}$ & $\begin{array}{l}56(9) \\
57(18) \\
66(8)\end{array}$ & $\begin{array}{l}0 \\
12(11) \\
6(4)\end{array}$ \\
\hline
\end{tabular}

CD45 isoform staining (CD45RA and RO) on CD3 + lamina propria lymphocyte T-cells as detected by three colour immunofluorescence. CD45RA was detected by FMC44PE. CD45RO was detected by UCHLl and indirectly stained with biotinylated goat anti-mouse immunoglobulin followed by Tandem-avidin, and CD3 was detected by Leu4-FITC. Files of 20000 cells were electronically gated to include only CD3 + cells and dot plots of CD45RA $v$ CD45RO staining generated. The number of positive cells in each quadrant was determined in comparison with identically gated samples stained with Leu4-FITC, IgG1PE, and IgG2a biotinylated goat anti-mouse Ig/Tandem avidin. Values are reported as mean $(\mathrm{SEM}) .{ }^{\star} \mathrm{p}<0.05 v$ normal; $\mathrm{p}$ value between all other pairs not significant.

FITC and PE were added directly and $25 \mu \mathrm{l}$ of buffer added. This was incubated for 30 minutes at $4^{\circ} \mathrm{C}$. Cells were washed three times and fixed with $1 \%$ formalin for flow cytometric analysis. Analysis of samples was performed on a FACScan (Becton-Dickinson). Dead cells and red cells were excluded by gating on forward angle light scatter and side scatter. All samples included staining with isotype matched control antibodies and unstained cells. List mode files were collected of 20000 cells from each sample, and measurements of all three fluorochromes as well as forward and side scatter were recorded.

\section{CALCULATIONS AND STATISTICAL METHODS}

To determine percentages of CD3 and CD19 peripheral blood lymphocytes and lamina propria lymphocytes expressing a specific marker, flow cytometry was performed on these populations. Three colour immunofluorescence data were collected in list mode from the analysis of each sample of lymphocytes. Data were then gated on the $\mathrm{T}$ or B-cell population of interest (CD3 or CD19) and the CD45 isoform expression of these respective populations were plotted as histograms using a Becton-Dickinson FACScan workstation with FACScan software, in comparison with an identically gated population, stained with CD3 or CD19 and isotype control monoclonal antibodies.

Of those patients with Crohn's disease whose peripheral blood lymphocytes were analysed, clinical parameters including the erythrocyte sedimentation rate, disease duration, drugs, disease location, age of the patient, and disease severity (presence or absence of fistulas or extraintestinal manifestations of disease) as well as the Crohn's disease activity index (CDAI) were obtained from chart review. ${ }^{27}$ Multiple regression analysis was performed by SPSS/PC + using these clinical variables with high or low molecular mass isoforms (CD45RA and/or CD45RO) CD45 and the combination of its isoforms as dependent variables. The Student's $t$ test was

TABLE II CD3+ Peripheral blood lymphocytes

\begin{tabular}{lllll}
\hline & $\begin{array}{l}C D 45 R A+R O- \\
(\%)\end{array}$ & $\begin{array}{l}R A+R O+ \\
(\%)\end{array}$ & $\begin{array}{l}R A-R O+ \\
(\%)\end{array}$ & $\begin{array}{l}R A-R O- \\
(\%)\end{array}$ \\
\hline Crohn's disease $(\mathrm{n}=21)$ & $34(5)$ & $10(2)$ & $37(5)$ & $16(4)^{\star}$ \\
Ulcerative colitis $(\mathrm{n}=11)$ & $44(3)$ & $19(3)$ & $37(4)$ & $0+$ \\
Coeliac disease $(\mathrm{n}=13)$ & $41(4)$ & $9(2)$ & $44(6)^{\star}$ & $4(3)^{\star}$ \\
Normal $(\mathrm{n}=7)$ & $44(6)$ & $9(3)$ & $42(3)$ & $1(0)^{\star}$ \\
\hline
\end{tabular}

Assessment of the CD45 isoform staining (CD45RA and RO) on CD3+ T-cells was detected by three colour immunofluorescence as described in Table I. Values are reported as mean (SEM).

${ }^{\star} \mathrm{p}<0.05$ Crohn's disease $v$ normal, Crohn's disease $v$ UC, Crohn's disease $v$ coeliac sprue; $p$ value between all other pairs not significant. used to compare CD45 isoform expression on $\mathrm{T}$ or B-cells between types of disease.

\section{Results}

PREDOMINANT EXPRESSION OF CD45RO ON CD3+ T-CELLS OF MUCOSAL LAMINA PROPRIA LYMPHOCYTES FROM NORMAL, CROHN'S DISEASE, AND ULCERATIVE COLITIS PATIENTS

Lamina propria lymphocytes isolated from fresh intestinal mucosa were analysed from normal and diseased tissue. Normal mucosa was derived from patients with diverticular disease, areas distal to neoplasms, and deceased organ donors. Lymphocyte profiles were not significantly different between these groups of patients. Normal lamina propria lymphocytes were stained by three colour immunofluorescence with antibodies to CD3, CD45RA, and CD45RO. After gating for CD3 + T-cells, the proportion of each isoform (CD45RA and CD45RO) on CD3 + cells was measured (Table I). The patterns of CD 45 isoform expression on CD3 + $T$ lamina propria lymphocytes from patients with Crohn's disease or UC was similar to those found among normal $\mathrm{T}$ lamina propria lymphocytes with a predominance of CD45RARO+ cells (mean (SEM) 66 (8)\%, Table I) confirming previous published work. ${ }^{2}$ Our ratio of CD45RA and CD45RO on normal and Crohn's disease lamina propria lymphocytes is consistent with published data. A confirmation of published works was necessary as a framework for comparing CD45 isoforms on B-cells to ensure our patients and normal controls did not vary from others. ${ }^{217}$

HETEROGENEITY OF CD45 ISOFORM EXPRESSION ON CD3 + T PERIPHERAL BLOOD LYMPHOCYTES FROM NORMAL, CROHN'S DISEASE, AND ULCERATIVE COLITIS PATIENTS

Normal PBMC were analysed, files were gated on $\mathrm{CD} 3+$, and CD45 isoform expression was assessed. No abnormalities in proportion of CD3, CD4 or CD8 cells were detected confirming previous reports. ${ }^{28}$ Normal patients PBMC included $44(6) \%$ CD45RA + RO- CD3 + cells, similar to that of UC (44 (3)\%) or Crohn's disease (34 (4)\%). No appreciable difference in CD45RA + RO+ or CD45RO- RA + lymphocytes were found between normal, Crohn's disease, and UC CD3+ PBMC (Table II). A detectable population lacking both CD45RA and RO was found among T-cells from Crohn's disease ( $16 \%$, Table II) but not among those in normal subjects, UC, or coeliac sprue. Because all T-cells express CD45 common determinants, the possibility exists that this reflects either expression of an isoform not detected by our monoclonal antibodies, for example CD45RB p190, or a change in glycosylation. Further work is needed to establish its significance.

ANALYSIS OF CD45 ISOFORMS OF CD19+ B LAMINA PROPRIA LYMPHOCYTES FROM NORMAL, CROHN'S DISEASE, AND UC PATIENTS

CD19 lamina propria lymphocytes from IBD 
TABLE III CD19+ Mucosal lymphocytes

\begin{tabular}{lllll}
\hline $\begin{array}{l}C D 45 \\
(\%)\end{array}$ & $\begin{array}{l}R A+R O- \\
(\%)\end{array}$ & $\begin{array}{l}R A+R O+ \\
(\%)\end{array}$ & $\begin{array}{l}R A-R O+ \\
(\%)\end{array}$ & $\begin{array}{l}R A-R O- \\
(\%)\end{array}$ \\
\hline $\begin{array}{l}\text { Crohn's disease }(\mathrm{n}=6) \\
\text { Ulcerative colitis }(\mathrm{n}=4)\end{array}$ & $\begin{array}{l}40(8) \\
45(13)\end{array}$ & $\begin{array}{l}21(7) \\
26(5)\end{array}$ & $\begin{array}{l}37(10) \\
29(16)\end{array}$ & $\begin{array}{l}2(1) \\
0(1)\end{array}$ \\
Normal $(\mathrm{n}=10)$ & $45(5)$ & $27(4)$ & $23(6)$ & $5(2)$ \\
\hline
\end{tabular}

$p$ Value between all pairs of data not significant.

CD45 isoform staining (CD45RA and RO) on CD19+ or CD20+ B-cell lamina propria lymphocytes as detected by three colour immunofluorescence. CD45RA was detected by FMC44PE. CD45RO was detected by UCHLI and stained indirectly with biotinylated goat anti-mouse immunoglobulin and Tandem-avidin, and CD19 by B4-FITC, or CD20 by B1-FITC. Similar results were obtained with Tandem-avidin, and CD19 by B4-FITC, or CD20 by B1-FITC. Similar results were obtained with Table I. The mean percentage of CD19+ B-cells in each disease studied were: normal blood donors mean $=8(0 \cdot 5) \%$, Crohn's disease mean $=10(5) \%$, UC mean $=8(5) \%$, consistent with published data. ${ }^{30}$ Values are reported as mean (SEM)

and from normal patients (organ donor, diverticulosis, and neoplasm resections) were analysed to determine expression of CD45RA and RO isoforms (Table III). A similar percentage of CD19+ B-lymphocytes (8-10\%) was found among the conditions studied as well as among normal patients.

On gut lamina propria lymphocytes, a range of CD45 isoforms were identified on CD19+ B-cells. As a group, UC, Crohn's disease, and normal lamina propria lymphocytes CD19+ $B$-cells include more cells bearing a transitional pattern of CD45 isoform expression (RA + RO+ ) or not bearing either isoform $(\mathrm{RA}-\mathrm{RO}-)$ than are found among circulating B-cells (Table III). Among normal lamina propria lymphocytes the CD45RA + RO - phenotype was detected on 45 (5)\% of $\mathrm{CD} 19+\mathrm{B}$ lymphocytes, identifying a mature resting B-cell population; $50-66 \%$ of B-cells in IBD and normal lamina propria lymphocytes expressed CD45RO, which appears on activated and late stage B-cells. ${ }^{918}$ Expression of CD45RO was found on $23 \%$ of normal lamina propria lymphocytes B-cells, consistent with definition as a late stage $B /$ preplasma cell. Coexpression of both CD45RA and CD45RO, consistent with definition as an activated $B$-cell, was found on $27 \%$ of normal lamina propria lymphocytes B-cells (Table III). Five per cent of normal CD19+ lamina propria lymphocytes lacked both CD45RA and RO.

INCREASED PROPORTION OF LATE STAGE CD45RO+ B-CELLS IN CD19+ B PBMC FROM CROHN'S DISEASE COMPARED WITH NORMAL DONORS OR COELIAC SPRUE AND UC PATIENTS

PBMC from Crohn's patients with detailed clinical descriptions were analysed in comparison with normal donors (Table IV). CD19+ B-cells from normal donor PBMC express almost exclusively CD45RA + RO-, consistent with our previous work. ${ }^{917}$ Similarly, B-cells from UC and coeliac sprue PBMC express this isoform

TABLE IV CD19+ Peripheral blood mononuclear cells

\begin{tabular}{|c|c|c|c|c|}
\hline $\begin{array}{l}C D 45 \\
(\%)\end{array}$ & $\begin{array}{l}R A+R O- \\
(\%)\end{array}$ & $\begin{array}{l}R A+R O+ \\
(\%)\end{array}$ & $\begin{array}{l}R A-R O+ \\
(\%)\end{array}$ & $\begin{array}{l}R A-R O- \\
(\%)\end{array}$ \\
\hline $\begin{array}{l}\text { Crohn's disease }(n=17) \\
\text { Ulcerative colitis }(n=11) \\
\text { Coeliac }(n=11) \\
\text { Normal }(n=9)\end{array}$ & $\begin{array}{l}58(9)^{\star} \\
98(0)^{\star} \\
96(1)^{\star} \\
99(1)^{\star}\end{array}$ & $\begin{array}{l}13(4) \dagger \\
2(0) \dagger \\
2(1) \dagger \\
0^{\star}\end{array}$ & $\begin{array}{l}15(5) \dagger \\
8(0) \dagger \\
1(0) \dagger \\
0^{\star}\end{array}$ & $\begin{array}{l}16(5) \dagger \\
0+ \\
0+ \\
0^{\star}\end{array}$ \\
\hline
\end{tabular}

CD45 isoform staining (CD45RA and RO) on CD19+ B-cell peripheral blood mononuclear cells as CD45 in (SEM).

( $<<0.005$ Crohn's disease $v$ normal, Crohn's disease $v$ UC, and Crohn's disease $v$ coeliac sprue. $\mathrm{tp}<0.05$ Crohn's disease $v$ UC and Crohn's disease $v$ coeliac sprue. almost exciusively (98 and $96 \%$ respectively). In contrast, PBMC from patients with Crohn's disease included $44 \%$ of B-cells with an abnormal phenotype, either lacking expression of CD45RA, or coexpressing CD45RA and CD45RO (Table IV). Fifteen per cent of CD19+ PBMC B-cells of patients with Crohn's disease expressed CD45RA - RO+, 13\% coexpressed both CD45RA and RO, and $16 \%$ were CD45RA - RO-. Thus, these B-cells have a CD45 isoform distribution consistent with their definition as a population of late stage antigen activated B lymphocytes.

The expression of CD45 isoforms on B-cells from Crohn's disease PBMC was very heterogeneous, unlike that from normal donors, UC or coeliac sprue. Figure 1 shows the consistently high and comparatively uniform CD45RA density on normal, UC, and coeliac sprue B-cells in contrast with the broad density distribution on PBMC B-cells from Crohn's disease. Crohn's B-cells included a clearly CD45RA negative population and a broad distribution of CD45RA+ cells. A similar degree of heterogeneity was evident for the CD45RO expression on B-cells (Fig 2). PBMC from Crohn's patients included a bimodal but heterogeneous population of CD45RO + B-cells with predominantly high antigen density (Fig 2). In general, those cells with a low intensity of CD45RO were those cells coexpressing CD45RA (Fig 1 and Table IV).

CD19+ B PERIPHERAL BLOOD LYMPHOCYTES FROM NORMAL AND CROHN'S DISEASE PATIENTS ARE CD11b- AND MAINLY CD5-

CD5 and CD11b expression on CD19+ B-cell PBMC from patients with Crohn's disease was analysed. No CD11b was found on CD19+ B-cell PBMC from patients with Crohn's disease, or on B-cells from normal donors. A low level of CD5 expression (mean $7(1) \%, n=19)$ was found on CD19+ $B$ peripheral blood lymphocytes in Crohn's disease patients, less than that found on B-cells from normal donors (mean $=30(5) \%, n=7$ ) (data not shown). As CD5 and CD11b have been shown to increase on the activation of B-cells the lack of either antigen on lamina propria lymphocytes B-cells argues against any activating effect of the procedures used to isolate lamina propria lymphocytes. ${ }^{4529}$

CORRELATION BETWEEN THE PROPORTION OF CD45RO+ B-CELLS AND SEVERITY OF CROHN'S DISEASE

Considerable variability was detected in the expression of CD45RA or RO among CD19+ PBMC from individual patients with Crohn's disease, in clear contrast with the normal pattern (Fig 3). To assess the clinical significance of this considerable variation in CD45RA and RO expression on $\mathrm{CD} 19+\mathrm{B}$-cells, clinical data were obtained on each patient. A number of parameters known to be associated with Crohn's clinical disease severity were tabulated, and multiple regression analysis was performed on these values using the statistical program SPSS $\mathrm{PC}+$. The B-cell subsets defined by CD45 


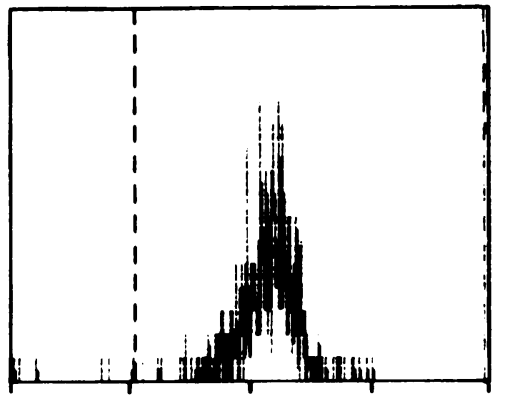

Normal

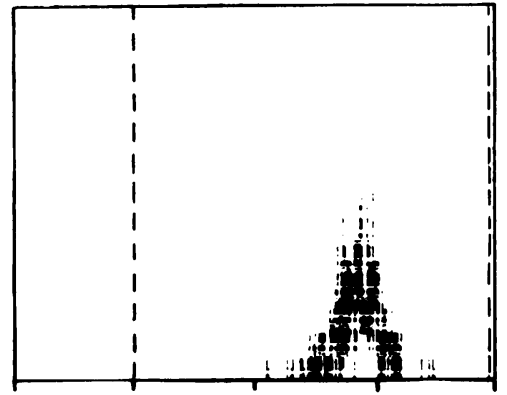

Coeliac sprue

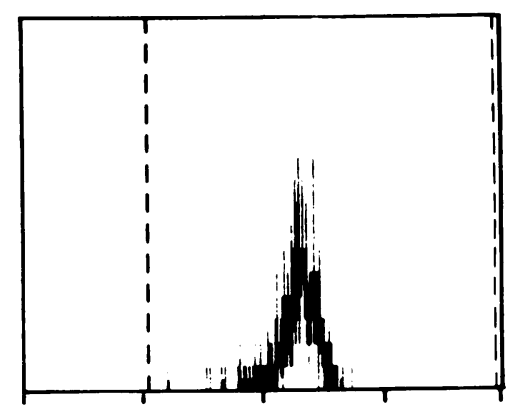

Ulcerative colitis

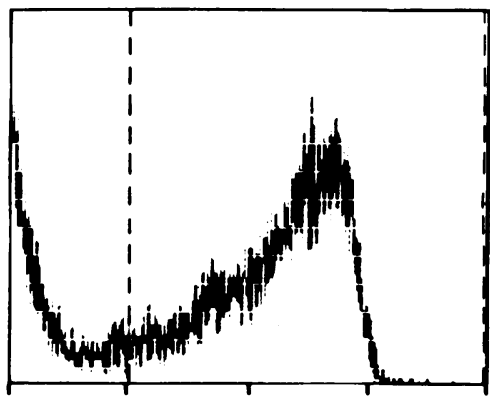

Crohn's disease
Figure 1: CD45RA expression on CD19+ PBMC B-cells. Normal, ulcerative colitis, and coeliac sprue FACScan histograms have consistently high and comparitively uniform expression of CD45RA in contrast with the heterogeneous distribution in peripheral blood mononuclear cells B-cells in Crohn's disease. Staining was as described in Table III. Files were gated for CD19+ cells and the distribution of CD45 isoform plotted. The vertical line denotes cell number and the horizontal axis the log fluorescence intensity. Cells were stained with CD19 or CD20 FITC, CD45RA PE, and CD45RO/biotinylated goat anti-mouse Ig/tandem-avidin. Files of 20000 cells were collected, and then gated for CD19+/20+ cells followed by a plot of CD45RA staining. Similar results were obtained with either CD19 or CD20.

isoforms, as dependent variables, were compared with the clinical parameters; Crohn's disease activity index (CDAI), disease duration, erythrocyte sedimentation rate, drugs, age of patient, and disease severity, as independent
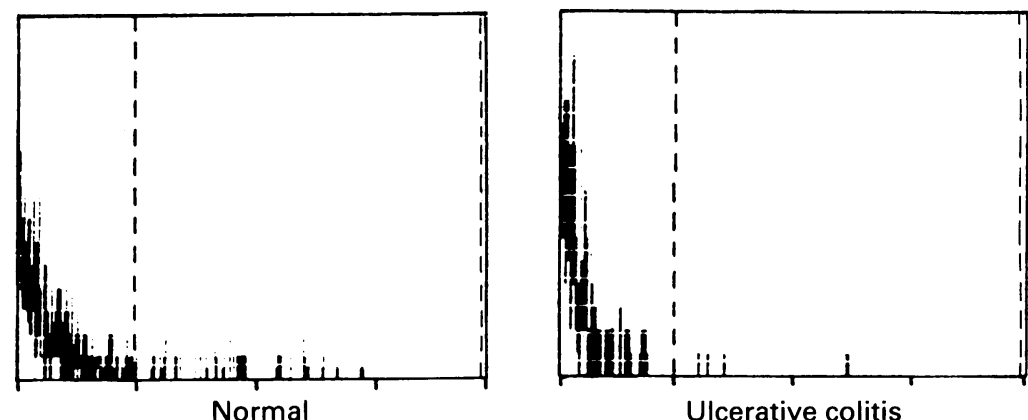

Ulcerative colitis

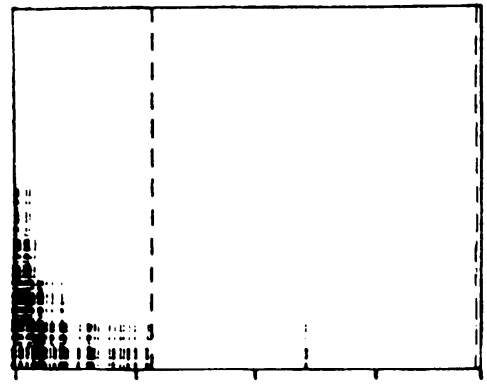

Coeliac sprue

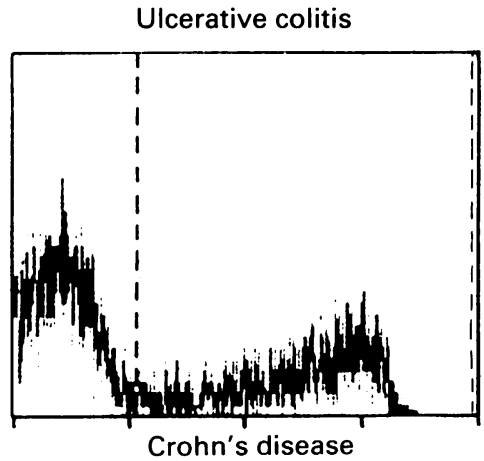

Figure 2: $C D 45 R O$ expression on $C D 19+P B M C B$-cells. Files were gated for $C D 19+$ or $C D 20+$ cells and the expression of CD45RO plotted as a histogram. Negligible expression of $C D 45 R O+$ is found on $C D 19+B$-cells from normal, coeliac sprue or ulcerative colitis patient peripheral blood. Peripheral blood mononuclear cells from Crohn's patients included a heterogeneous population of $C D 45 R O+B$-cells with predominantly high antigen density. Similar results were obtained with either CD19 or CD20. Staining and analysis were as for Figure 1. variables. CD45RO+ B-cells were divided into two groups, group 1 included B-cells expressing $0-49 \%$ CD $45 \mathrm{RO}+$. Group 2 included all patients with B-cells having $50 \%$ and greater $\mathrm{CD} 45 \mathrm{RO}+$ expression. These values were compared with the respective CDAI values for each patient, showing the means of the two groups to be significantly different using the two sample $t$ test (group 1 mean $=108 \cdot 2, \mathrm{SE}=16 \cdot 5)$ (group 2 mean $=179 \cdot 0, \mathrm{SE}=27 \cdot 4)\left(\mathrm{n}_{1}=23, \mathrm{n}_{2}=6, t=2 \cdot 01\right.$, 2 tail $p=0.05)$. Furthermore, there is a grouping of high values of CD45RA - RO+ with high CDAI values and vice versa. No other combination of parameters or any B-cell phenotype had such a significant relation. When CDAI was graphed against CD45RO, however, the relation was not linear, with some patients having high CDAI expressing low CD45RO on their CD19 cells and vice versa, suggesting that other parameters participate in the degree of expression of CD45RO on B-cells.

\section{Discussion}

In this report we have focused on the expression of CD45 and its isoforms RA and RO on PBMC or lamina propria lymphocytes, or both from a variety of intestinal diseases including Crohn's disease, UC, coeliac sprue, and normal control patients. Previous studies have been limited to immunohistochemical quantification of the CD45 isoforms on T-cells, or to heightened lymphocyte activation in peripheral blood not specific to Crohn's disease. ${ }^{3417} 30$

Differences in immunoglobulin isotype production by lamina propria lymphocytes from patients with Crohn's disease compared with lamina propria lymphocytes from UC and normal controls has been shown by others, but this difference cannot be a result of cell activation alone because differentiated cells and not activated replicating cells are responsible for most of the immunoglobulin production. ${ }^{21}$ Moreover, recognition of the expression of CD45RO on B-lymphocytes has been recent and until this report, primarily associated with some normal B-cells from aged adults, in vitro stimulated B-lymphocytes, and malignant B-cells. ${ }^{918} 19^{2431}$ Acquisition of CD45RO isoform on B-lineage cells occurs after in vitro stimulation $^{918}$ confirming the in vivo transition from CD45RA to CD45RO, a process accentuated in lamina propria lymphocytes and Crohn's disease PBMC. This study identifies a unique population of non-malignant $\mathrm{CD} 45 \mathrm{RO}+\mathrm{CD} 19+$ PBMC that to date have been identified only after in vitro stimulation and in PBMC from patients with multiple myeloma, Waldenstrom's macroglobulinaemia, and chronic lymphocytic leukaemia. ${ }^{31} 32$

Our analysis of CD3 + lamina propria lymphocytes from the normal intestine confirms the prevalence of CD45RO as the predominant isoform (66 (8)\%). Comparatively few antigen inexperienced (CD45RA +) or transitional forms $(\mathrm{CD} 45 \mathrm{RA}+\mathrm{RO}+)$ were identified in normal lamina propria lymphocytes $(9(2) \%$ and $19(4) \%$ respectively). These findings are consistent with previous published work.' This consistency with accepted published works was necessary to 


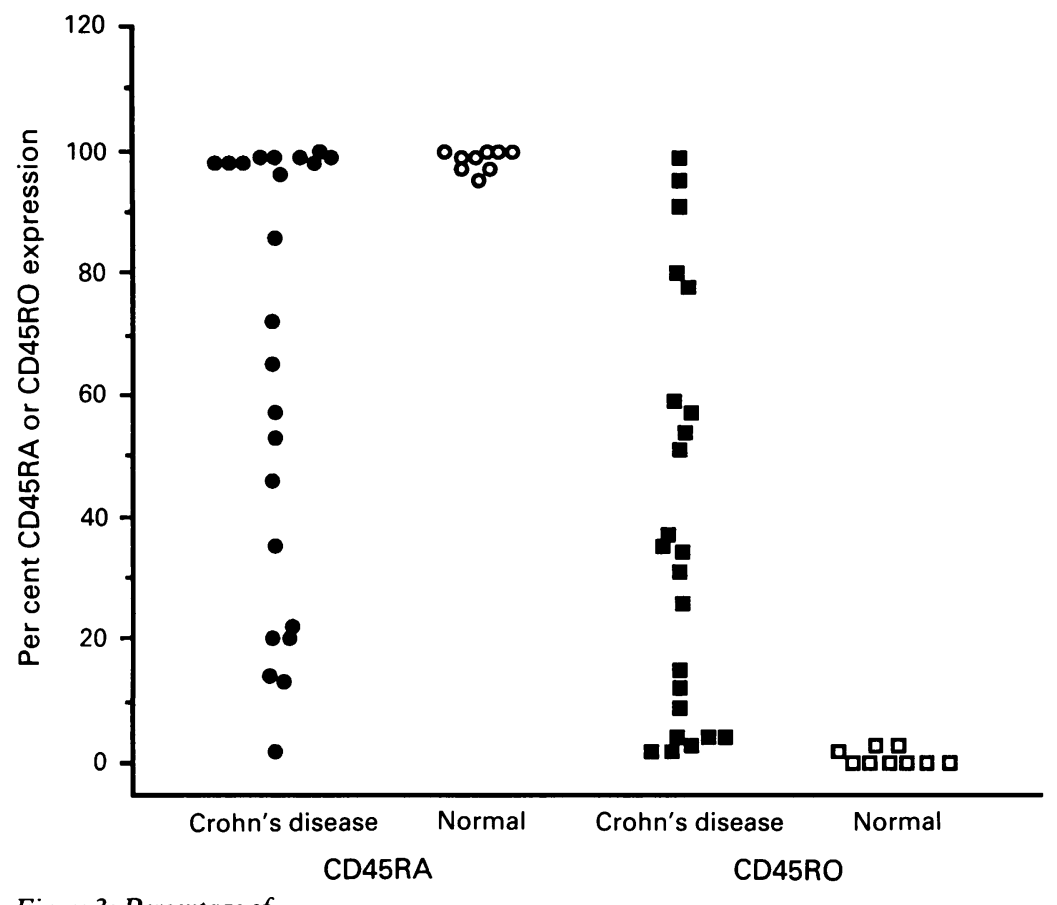

Figure 3: Percentage of $C D 19+C D 45 R A+$ or $\mathrm{CD} 19+\mathrm{CD} 45 \mathrm{RO}+$

$B$-cells in Crohn's disease v normal peripheral blood mononuclear cells. Staining was as described in Figure 1 . provide a framework to compare CD45 isoforms on B-cells in these same patients.

B-cells from organ tissue (including spleen, lymph node, and thymus) also express CD45RA but unlike normal PBMC, these tissues also express a substantial proportion of CD45RO.' This may be as a result of their role as immunological responders to environmental antigens, given the presence of germinal centres in these tissues. Our data identify normal intestinal lamina propria lymphocytes as another tissue with a proportion of B-lymphocytes expressing $\mathrm{CD} 45 \mathrm{RO}$, probably because of the continuous antigen exposure of normal intestine. In contrast with the pattern of CD45 isoform expression among circulating B-cells in PBMC, equal expression of CD45RA and RO is found in normal CD19+ lamina propria lymphocytes. The pattern of CD45 isoforms on CD19+ lamina propria lymphocytes from inflamed, diseased IBD tissue closely resembled normal intestine, although some patients with Crohn's disease had increased numbers of CD45RO + B-cells, however this difference was not statistically significant. CD19+ lamina propria lymphocytes B-cells from normal or diseased intestine have not been previously analysed specifically for CD45 isoform expression. The shift of B-cell CD45 isoforms, however, to a more terminally differentiated population in the gut mucosa is consistent with the heightened immune activation in gut found by others. ${ }^{+29}$ This comfirms that intestinal B-cells comprise an antigen stimulated subset at later stages of differentiation than seen for peripheral blood B-cells compatible with the activated state of normal intestine lamina propria lymphocytes.

$\mathrm{CD} 45 \mathrm{RA}+\mathrm{RO}+$ as well as $\mathrm{RA}-\mathrm{RO}-$ subset phenotypes were-represented among CD19+ PBMC from patients with Crohn's disease in contrast with UC or normal PBMC. This pattern of CD45RO+ and transitional isoform expression suggests a population of activated or late stage B-cells as might be predicted if they play a part in the general heightened immune response associated with Crohn's disease. This heterogeneity of CD45 expression on CD19+ PBMC from patients with Crohn's disease was statistically studied with a number of clinical parameters (including the CDAI, disease duration, extraintestinal disease, disease location (colon, small bowel, colon and small bowel), erythrocyte sedimentation rate, drugs, and age of patient) by multiple regression analysis to determine if any of these variables could account for the aberrant pattern of CD45 isoform expression found on this population of PBMC. Of these clinical parameters, the CDAI was found to be statistically correlated with significance to the CD45RA - RO+ subpopulation of CD19+ PBMC in Crohn's disease. When CD45RO+ $\mathrm{B}$-cell expression is graphed against the CDAI, however, the pattern obtained does not seem linear. This may be due to CD45RO expression being related to another variable such as changed intestinal permeability. Moreover, the CDAI is known to vary as a measurement of Crohn's disease severity and this also contributes to the dispersed appearance of the graph. Further studies of CD45RO in Crohn's peripheral blood lymphocytes are in progress and may show a more linear relation with other variables.

Although other explanations are possible, the most plausible suggests that the apparent correlation of CD45RA - RO + CD19+ PBMC with the CDAI results from a stimulated immune system in more severely ill patients either as a primary event initiating intestinal inflammation or as part of an inflammatory cascade once inflammation has started. CD5 and CD11b were absent from lamina propria lymphocytes or PBMC B-cells suggesting these represent late stage B-cells rather than cells in the process of activation, which would express both antigens based on patterns of activation in vitro. ${ }^{9}$ Recent work by MacDonald has shown an activated submucosal T-cell population in Crohn's disease patients intestine. Such a population could provide the necessary help to result in the high proportion of late stage and transitional B-cells found in Crohn's disease. ${ }^{33}$ To our knowledge, no other population of differentiated, mature PBMC has been identified exclusively in patients with Crohn's disease. Drugs used could not explain the exclusive expression of CD45RO on B-cells in Crohn's disease because the same drugs were used in UC without CD45RO being found. Additionally, no statistical correlation with a specific drug could be identified to account for the presence of CD45RO+ B-cells.

Our finding of a trend towards an increased proportion of $\mathrm{CD} 45 \mathrm{RO}+$ and transitional lamina propria lymphocytes in Crohn's disease may reflect the increased accessibility of antigens to lamina propria lymphocytes in Crohn's disease because of the transmural inflammation characteristic of this illness. Alternately, the abnormal immune response identified in Crohn's disease may permit antigen penetration through mucosa resulting in increased lamina propria lymphocytes B-cell transition to the CD45RO isoform. The prevalence of the CD45RO isoform almost exclusively on CD19+ PBMC of patients with Crohn's disease thus may be due to a 'spill 
over' of these transitional B-cells from gut into blood.

In conclusion, we have recorded the expression of CD45RO on circulating PBMC B-cells exclusive to IBD patients with Crohn's disease. The presence of high numbers of late stage $\mathrm{CD} 45 \mathrm{RO}+$ lymphocytes in the gut has been identified previously. ${ }^{317}$ Our identification of $\mathrm{CD} 45 \mathrm{RO}+$ and transitional CD45 isoform $\mathrm{B}$-cells in peripheral blood, however, defines a new cellular population of interest in IBD.

The authors thank Wendy McEachern for her excellent manuscript preparation, Kasia Matejko for her skilled technical assistance, and Dennis Bray for statistical analysis. Special thanks to Dr Mary Beth Bowen-Yacyshyn for valuable criticism of the manuscript.

This work was supported by the Medical Services Incorporated (MSI) Foundation and Grawin Foundation (BRY) and the Medical Research Council of Canada (LMP)

1 Hamilton SR. Diagnosis and comparison of ulcerative colitis and Crohn's disease involving the colon. In: Norris HT, ed. Pathology of the colon, small intestine and anus. New York: Churchill Livingstone, 1983: 1-19.

2 James SP, Fiocchi A, Graeff AS, Strober W. Phenotypic analysis of lamina propria lymphocytes. Gastroenterology 1986; 91 : 1483-9.

3 Pallone F, Fais S, Squarcia O, Biancone L, Pozzilli P, Boirivant $M$. Activation of peripheral blood and intestinal lamina propria lymphocytes in Crohn's disease. In vivo state of activation and in vitro response to stimulation as defined by the expression of early activation antigens. Gut 1987; 28: by the expr.

4 Schreiber S, MacDermott RP, Raedler A, Pinnau R Bertovich MJ, Nash GS. Increased activation of isolated
intestinal lamina propria mononuclear cells in inflammatory intestinal lamina propria mononuclear cells in inflam

5 Yacyshyn BR. Activated CD19+ B-cell Lamina propria lymphocytes in ulcerative colitis. $\mathcal{F}$ Immunol Cell Biol (in press).

6 Pallone F, Matricardi PM, Squarcia P, Fais S, Le Moli S Boirivant $M$, et al. Raised serum levels of IgM-Rheumatoid factor and Anti $\mathrm{F}\left(\mathrm{ab}^{1}\right) 2$ autoantibodies in patients with active inflammatory bowel disease. F Clin Lab Immunol 1986; 19: 175-80.

7 Vecchi M, Sakamaki S, Das KM. Organ specificity and colonic distribution of the Mr 40000 colonic protein associated with ulcerative colitis: Tissue localization using a specific monoulcerative colitis: Tissue localization using a specific mono-
clonal antibody. In: MacDermott RP, ed. Inflammatory clonal antibody. In: MacDermott RP, ed. Inflammatory bowel disease: current status and futur

8 Shanahan F, Duerr RH, Rotter JI, Yang H, Sutherland LR, McElree C, et al. Neutrophil autoantibodies in ulcerative colitis: familial aggregation and genetic heterogeneity. Gastroenterology 1992; 103: 456-61.

9 Pilarski LM, Jensen GS. Expression of CD45 isoforms (leukocyte common antigen) and adhesion molecules during normal and abnormal human B lymphocyte development. In: Singh B, ed. Advances in molecular and cellular immunology. Vol l. (in press).

10 Marcos MAR, Toribio M, De La Hera A, Marquez C, Gaspar M, Martinez AC. Mutual cell interactions and the selection $M$, Martinez AC. Mutual cell interactions and the selection
of immune repertoires: implication in autoimmunity. of immunol Today 1988; 9: 204-7.

11 Trowbridge IS. Interspecies spleen-myeloma hybrid producing monoclonal antibodies against mouse lymphocyte surface glycoprotein T200. F Exp Med 1978; 148: 313-23.

12 Thomas ML. The leukocyte common antigen family. Ann Rev Immunol 1989; 7: 339-70

13 Woolett GR, Barclay AN, Puklavec M, Williams AF Molecular and antigenic heterogeneity of the rat leukocyte common antigen from thymocytes and $\mathrm{T}$ and $\mathrm{B}$ lymphocytes. Eur F Immunol 1985; 15: 168-73.
14 Dalchau R, Fabre JW. Identification with a monoclonal antibody of a predominantly $\mathrm{B}$ lymphocyte-specific determinant of the human leukocyte common antigen. f Exp Med 1981; 153: 753-65.

15 Serra HM, Krowka JF, Ledbetter JA, Pilarski LM. Loss of CD45R (p220) represents a post-thymic T-cell differentiation event. F Immunol 1988; 140: 1435-41.

16 Pilarski LM, Deans JP. Selective expression of CD45 isoforms and maturation antigens during human thymocy to differentiation: observations and hypothesis. Immunol Letts 1989; 21: 187-98.

17 Brandtzaeg P, Bosnes V, Halstensen TS, Scott H, Sollid LM, Valnes KN. T-lymphocytes in human gut epithelium preferValnes KN. T-lymphocytes in human gut epithelium prefer-
entially express the $\alpha / \beta$ antigen receptor and are often CD45/ entially express the $\alpha / \beta$ antigen receptor and are often
UCHLI-positive. Scand 7 Immunol $1989 ; 30: 123-8$.

18 Jensen GS, Poppema S, Mant MJ, Pilarski LM. Transition in $\mathrm{CD} 45$ isoform expression during differentiation of norma and abnormal B-cells. Int Immunol 1989; 1: 229-36.

19 Pilarski LM, Jensen GS. Monoclonal circulating B-cells in multiple myeloma: a continuously differentiating possibly invasive population as defined by expression of CD4 isoforms and adhesion molecules. Hematol Oncol Clin North Am 1992; 6: 297-322.

20 Bookman MA, Bull D. Characteristics of isolated intestina mucosal lymphoid cells in inflammatory bowel disease. mucosal lymphoid cells in infla
Gastroenterology 1979; 77: 503-10.

21 MacDermott RP, Nash GS, Bertovich MJ, Mohrman FR Kodner IJ, Delacroix DL, et al. Altered patterns of secretion of monomeric IgA and IgA subclass 1 by intestinal mononuclear cells in inflammatory bowel disease. Gastroenterology 1981; 91: 379-85.

22 MacDermott RP, Nash GS, Bertovich MJ, Seiden MV Bragdon MJ, Beale MG. Alterations of IgM, IgG and IgA synthesis and secretion by peripheral blood and intestina mononuclear cells from patients with ulcerative colitis and Crohn's disease. Gastroenterology 1981; 81: 844-52.

23 Pilarski LM, Gillitzer R, Zola H, Shortman K, Scollay R. Definition of the thymic generative lineage by selective expression of high molecular weight isoforms of CD45 (T200). Eur F Immunol 1989; 19: 589-97.

24 Jensen GS, Mant MJ, Belch JJ, Berenson JR, Reuther BA Jensen GS, Mant MJ, Belch JJ, Berenson JR, Reuther BA,
Pilarski LM. Selective expression of CD45 isoforms defines Pilarski ${ }^{+} \mathrm{M}$. Selective expression of $\mathrm{CD} 45$ isoforms defines
$\mathrm{CALLA}^{+} \mathrm{B}$ lineage cells in peripheral blood from myeloma patients as late stage B cells. Blood 1991; 78: 711-9.

25 Deans JP, Boyd AW, Pilarski LM. Transitions from high to low molecular weight isoforms of CD45 involve rapid activation of alternate mRNA splicing and slow turnover of surface CD45R. F Immunol 1989; 143: 1233-8.

26 Streuli M, Morimoto C, Schrieber M, Schlossman SF, Saito H. Characterization of CD45 and CD45R monoclonal antibodies using transfected mouse cell lines that express individual human leukocyte common antigens. 7 Immunol 1988; 141: 3910-4.

27 Best WR, Beckel JM, Singleton JW, Kern F. Development of a Crohn's disease activity index. National Cooperative Crohn's Disease Study Group. Gastroenterology 1976; 70: 439-44.

28 Yuan S, Hanauer SB, Kluskens LF, Kraft SC. Circulating lymphocyte subpopulations in Crohn's disease. Gastroenterology 1983; 85: 1313-8.

29 Peters M, Anders KR, Nash GS, Zhelezniak A, MacDermot RP. Activation of intestinal mononuclear cells. In MacDermott RP, ed. Current status and future approach. Amsterdam: Excerpta Medica, 1988: 67-72.

30 Raedler A, Fraenkel S, Klose G, Seyfarth K, Thiele HG. Involvement of the immune system in the pathogenesis of Crohn's disease. Gastroenterology 1985; 88: 978-83.

31 Maddy AH, Sanderson AD, Mackie MJ, Smith SK. The role of cell maturation in the generation of phenotypic heterogeneity in B cell chronic lymphocytic leukemia. Immunology geneity in B cell chro

32 Jensen GS, Andrews EJ, Mant MJ, Vergidis R, Ledbetter JA Pilarski LM. Transitions in CD45 isoform expression indicate continuous differentiation of a monoclonal CD5 $\mathrm{CD} \mathrm{b}^{+} \mathrm{B}$ lineage in Waldenstrom's macroglobulinemia. Am F Hematol 1991; 37: 20-30.

33 Choy MY, Walker-Smith JA, Williams CB, MacDonald TT. Differential expression of CD25 (interleukin-2 receptor) on lamina propria T-cells and macrophages in the intestinal lesions in Crohn's disease and ulcerative colitis. Gut 1990; 31: $1365-70$ 